\begin{tabular}{|l|l|l||}
\hline \multicolumn{2}{|c|}{ PublisherInfo } \\
\hline \hline PublisherName & $:$ & BioMed Central \\
\hline \hline PublisherLocation & $:$ & London \\
\hline \hline PublisherImprintName & $:$ & BioMed Central \\
\hline \hline
\end{tabular}

\title{
Mitochondrial DNA recombines
}

\begin{tabular}{|l|c|l||}
\hline \multicolumn{2}{|c|}{ ArticleInfo } \\
\hline \hline ArticleID & $:$ & 4952 \\
\hline \hline ArticleDOI & $:$ & $10.1186 /$ gb-spotlight-20040514-01 \\
\hline \hline ArticleCitationID & $:$ & spotlight-20040514-01 \\
\hline \hline ArticleSequenceNumber & $:$ & 304 \\
\hline \hline ArticleCategory & $:$ & Research news \\
\hline ArticleFirstPage & $:$ & 1 \\
\hline \hline ArticleLastPage & $:$ & 3 \\
\hline \hline & & RegistrationDate : 2004-5-14 \\
\hline ArticleHistory & $:$ & OnlineDate \\
\hline \hline ArticleCopyright & $:$ & BioMed Central Ltd2004-5-14 \\
\hline \hline ArticleGrants & $:$ & \\
\hline \hline ArticleContext & $:$ & 130594411 \\
\hline \hline
\end{tabular}


Cathy Holding

Email: cathyholding@aol.com

Recombination occurs in human mitochondrial DNA, says a team from the Beth Israel Deaconess Medical Center and Harvard Medical School, Boston, in a "proof of concept" paper in Science this week that they say overturns current dogma of maternal inheritance and non-recombination.

Investigating the basis for a mitchondrial myopathy in a patient described in 2002, members of Kraytsberg's group had discovered that his muscle contained about $90 \%$ paternal mtDNA carrying a detrimental mutation responsible for the disease, Khrapko told us by email.

Using a restriction enzyme recognizing only paternal sequence, and single-molecule polymerase chain reaction (PCR) to amplify it, 33 out of 450 PCR clones from the subject's muscle tissue were found to contain both maternal and paternal sequence. Several recombinants contained more than one breakpoint - segments that join polymorphisms of different (paternal/maternal) descent - and three breakpoint hotspots were described as "highly significant."

"The relevance of our results to evolution studies is purely conceptual, i.e. it gives other researchers who are really in the position to address the population-related issues, the hint that recombination needs to be considered as a potential factor in their studies," said Konstantin Khrapko, the team's leader.

The work has "exciting implications for mitochondrial DNA repair and replication," he said. However, the results do not challenge the idea that human maternal mitochondrial DNA changes only very slowly over time and consists solely of genetic material from the mother, Khrapko said. "It does not challenge the idea of a mitochondrial DNA molecular clock or structure of genealogical trees."

"What [the authors] have done is very rigorous with respect to ensuring that what they are observing are truly recombination events," said Philip Awadalla, professor of genetics at North Carolina State University. Awadalla told us that a lot of history and dogma lies behind the notions of strict maternal inheritance and lack of recombination, in particular in human mitochondrial DNA.

John Maynard Smith first challenged this dogma by looking at human population genetic data. "The implications of recombination from both a biological and population genetics perspective can be dramatic, depending on how frequently this occurs," said Awadalla, who was not involved in the study.

"We need to know whether mitochondria are strictly inherited from one parent and we need to know if they recombine," said Adam Eyre-Walker, co-director of the Centre for the Study of Evolution at Sussex University. "These are basic processes going on in mitochondria and as such they are of interest," he said. "But they are not going to overturn our view of human evolution. The implications are not that dramatic."

"The work does not demonstrate either paternal inheritance or recombination occurring in the germ line," said Eyre-Walker, who was not involved in the study. "So this is an evolutionary dead-end. This individual will not pass on these recombinant molecules to his offspring."

Khrapko acknowledged that recombinants were found only in muscle, and that the work provided no evidence of inheritability of recombinants. 
Still, said Awadalla, at some point the recombinants will have passed through the germline. "Well, it must have come from somewhere, and if [the authors] have demonstrated that this individual has these two copies [of mitochondrial DNA sequence] and its recombinants, then one of the original paternal copies came from the paternal lineage."

"One possibility is that a small amount of defective paternal DNA, that was introduced during fertilization, got selective advantage in the muscle due to this detrimental mutation and/or paternalspecific polymorphisms," Khrapko said.

Eyre-Walker offered another theory: "One aspect of this may be that a little bit of paternal leakage actually is generating a slightly higher mutation rate, so it's possible that a proportion of the mutations we see in mitochondrial DNA are actually generated from these paternal leakage events - which would be intriguing."

Eyre-Walker told us that "the work could have implications for dating our most recent female common ancestor sometimes referred to as Eve."

"You can date [her] by using mitochondrial DNA because it appears to be inherited solely through the maternal line," he said. "It will change that picture."

\section{References}

1. Science, [http://www.sciencemag.org/]

2. Paternal inheritance of mitochondrial DNA

3. Konstantin Khrapko, [http://www.bidmc.harvard.edu/display.asp?node_id=3010\&leaf_id=4876]

4. Philip Awadalla, [http://www.cals.ncsu.edu/genetics/awadalla/awadalla.html]

5. Brahic C: John Maynard Smith dies Genome Biology, April 27, 2004., [http://genomebiology.com/ researchnews/default.asp?arx_id=gb-spotlight-20040427-01]

6. Adam Eyre-Walker, [http://www.lifesci.sussex.ac.uk/CSE/members/aeyrewalker/aeyrewalker.htm]

7. The search for Eve

This PDF file was created after publication. 